\title{
Hacia una clasificación de grano fino de los verbos de movimiento. El caso de los verbos intransitivos del español
}

\author{
Towards a Fine Grained Classification of Motion Verbs. \\ The Case of Spanish Intransitive Verbs
}

\author{
Sergio Ibáñez Cerda \\ Universidad Nacional Autónoma de México \\ cecser@prodigy.net.mx
}

\begin{abstract}
Bertha Lecumberri Salazar
Posgrado en Lingüística, Universidad Nacional Autónoma de México bertha.lecumberri@gmail.com
\end{abstract}

Resumen

A partir de los patrones de lexicalización presentados en el trabajo pionero de Talmy (1985), las clasificaciones que en la bibliografía se suelen ofrecer para los verbos de movimiento del español reconocen principalmente dos grupos: verbos de movimiento y verbos direccionales o de desplazamiento (Lamiroy, 1991; Cifuentes Honrubia, 1988-1989; Crego García, 2000; Morimoto, 2001, entre otros). La presente investigación ofrece una clasificación más detallada mediante el recurso a un juego más fino de rasgos y participantes semánticos susceptibles de ser lexicalizados en los verbos de movimiento de cualquier lengua del mundo, a saber: los rasgos aspectuales de puntualidad y telicidad; los participantes tema, fuente, ruta, meta, punto de referencia, locación-ruta y trayectoria; y los rasgos paramétricos de desplazamiento, movimiento, manera, cambio de lugar y dirección. El resultado es una clasificación de ocho grupos distintos que dan cuenta de los mecanismos léxicos y sintácticos presentes en la codificación de los eventos de movimiento del español.

Palabras Clave: movimiento, estructura argumental, patrones de lexicalización, interfaz semántico-sintáctica, verbos del español

Abstract

Based on the lexicalization patterns presented in Talmy's pioneering work (1985), motion verbs classifications for Spanish mainly recognize two groups: verbs of manner and verbs of direction (Lamiroy, 1991; Cifuentes Honrubia, 1988-1989; Crego García, 2000; Morimoto, 2001, among others). This research offers a much more detailed classification, by means of the use of a finer set of features and semantic participants that may be lexicalized by motion verbs in any language of the world, namely: the aspectual features of punctuality 
and telicity; the participants theme, source, path, goal, point of reference, location-path and trajectory; and the parametric features of displacement, movement, manner, change of place and direction. The result is a classification of eight different verb groups that account for the lexical and syntactic mechanisms present in the encoding of the Spanish motion events.

KEYwORDS: motion verbs, argument structure, lexicalization patterns, Syntax-semantics interface, Spanish verbs

FECHA DE RECEPCIÓN: 23/01/2019

FECHA DE ACEPTACIÓN: 15/05/2019

\section{Introducción}

Desde Talmy (1985), la noción de movimiento y su codificación en las lenguas ha sido estudiada con una perspectiva tipológica por medio de la cual se han tratado de identificar los patrones de lexicalización más básicos en términos de sus efectos sintácticos. Esta tipología ha servido de base para muchos estudiosos en la descripción de verbos de movimiento en una buena cantidad de lenguas de muy diversa identidad genética y areal (Aske, 1989; Slobin, 1996; Verspoor, Dirven y Radden, 1999; Rohde, 2001; Evans y Tyler, 2004, Stefanowitsch y Rohde, 2004; Zwarts, 2010 , entre muchos otros). Sin embargo, cuando uno se acerca de forma detallada al estudio interno de paradigmas léxicos en lenguas con inventarios ricos en verbos de movimiento, como es el caso del español y de muchas otras lenguas, la tipología de rasgos de Talmy, aunque efectiva en grosso modo, no permite la distinción de rasgos más finos que no solo ayudan a distinguir paradigmáticamente los verbos del dominio en la lengua bajo estudio, sino que muestran efectos en el comportamiento sintáctico y permiten hacer clasificaciones más detalladas en términos de los patrones de complementación de los verbos con los distintos argumentos locativos (meta, fuente, locación y ruta).

Tomando lo anterior como punto de partida, el objetivo del presente trabajo es hacer una revisión minuciosa de los rasgos semánticos presentes en los verbos de movimiento que codifi- 
can desplazamiento espacial en español; se revisarán dos puntos principales: en primer lugar, a partir de las propuestas de Jackendoff (1983), Talmy $(1985,2000)$ y de otros estudios, en particular Ibáñez (2005) y Lecumberri (2011), se hará una revisión detallada de los rasgos semánticos que, de manera independiente, forman parte de los distintos patrones de lexicalización en el español; en segundo lugar, se propone una clasificación más detallada de los verbos de movimiento del español a partir de los patrones de lexicalización identificados y de los efectos que estos tienen en la complementación argumental de los verbos en cuestión.

El foco del trabajo es en los eventos dinámicos de movimiento autocausado. Quedan fuera del alcance de este las expresiones espaciales estativas (estar en la casa), los eventos de cambio de postura o posición (arrodillarse) y también, por efecto de espacio, todas las construcciones causativas, como son las de cambio de locación puntual (del tipo de poner), como las que implican desplazamiento (del tipo de llevar).

Los componentes o formantes de los eventos de movimiento que se tomarán en cuenta para el análisis pueden dividirse en tres tipos:

- Participantes dinámicos: tema y causante.

- Participantes locativos: fuente, ruta, meta, locación y punto de referencia. ${ }^{1}$

- Rasgos paramétricos o inherentes: ${ }^{2}$ movimiento, desplazamiento, manera, dirección y cambio de lugar.

- Rasgos aspectuales: telicidad y puntualidad.

A partir del estudio detallado de estos componentes y las distintas interacciones entre ellos, el presente estudio propone

\footnotetext{
${ }^{1}$ Se trata de una categoría que introducimos en este trabajo y que da cuenta de complementos tipo 'ruta' que aparecen con verbos puntuales. Ver más abajo en el apartado 2.2.

${ }^{2}$ Los rasgos paramétricos son rasgos distintivos inherentes que permiten identificar a cada uno de los ítems léxicos de la clase y que cuando se expresan sintácticamente lo hacen como modificadores, no como argumentos (Ibáñez, 2005).
} 
una nueva clasificación de los verbos de movimiento del español; dicha clasificación facilita el análisis del comportamiento sintáctico de los predicados.

\section{Antecedentes}

Entre los estudios tipológicos más significativos en el estudio del movimiento y los predicados vinculados con dicho dominio, se encuentran las investigaciones de Jackendoff (1983) y Talmy $(1985,2000)$.

En el estudio sobre la semántica de los eventos espaciales, Jackendoff propone que las expresiones lingüísticas pueden referir tanto a estados (sTATE) como a eventos (EVENT). En una lengua como el inglés, en los estados, las frases preposicionales cumplen una función-PLACE, mientras que con los eventos cumplen la función-PATH. Adicionalmente, Jackendoff reconoce los componentes semánticos THING, PLACE y PATH. El primero de ellos, se refiere a las entidades referenciales; puede ser la figura del movimiento o puede representar el objeto de una función de tipo PLACE (i.e. una locación), que en lenguas como el español o el inglés se codifica como una frase nominal, generalmente en función sujeto u objeto directo. El concepto PLACE puede representarse como un adverbio (i.e. here) o bien con una frase preposicional de tipo on the table en la que hay una palabra referencial table (THING), que adquiere la función PLACE mediante una preposición locativa, como on del inglés. Existen diferentes funciones-PLACE, cada una de las cuales selecciona un tipo de referente específico (e.g. la función-PLACE IN requiere una locación delimitada).

Por otra parte, en los trabajos de Talmy (1985, 2000), el movimiento es entendido a partir de un marco nocional-conceptual, pero en términos de los efectos sintácticos que los predicados de esta área de significado muestran en una perspectiva tipológica. La estructura del movimiento (motion situation) tiene seis componentes semánticos: figura, fondo, movimiento, path, manera y causa. Las cuatro primeras son categorías pri- 
marias, mientras que la manera y la causa son secundarias. La figura, equivalente al THING de Jakendoff, es la entidad que se desplaza en relación con otra; el fondo o base (ground), similar a la noción de PLACE, es el lugar respecto del cual la figura se desplaza o se localiza; el path es el camino y/o dirección que sigue la figura que se desplaza, respecto del fondo, es decir, es la trayectoria de la figura; la manera se refiere a la forma en que la figura se mueve; y, por último, la causa es la entidad externa que inicia o impulsa el movimiento de la figura. En lenguas como el español o el inglés, los componentes figura y fondo suelen expresarse a través de formas nominales; en el caso del fondo, se trata de frases nominales que son término de preposición; el componente path, o bien se manifiesta a través de preposiciones (y de frases preposicionales), y/o es parte inherente del significado del predicado; el movimiento, por su parte, es un componente lexicalizado en las formas verbales.

A partir de estos componentes, Talmy hace una clasificación tipológica según el trato léxico y/o morfosintáctico preferente que las distintas lenguas del mundo dan a los componentes semánticos: por un lado, lenguas como el chino y como las indoeuropeas, a excepción de las romances, funden en la forma verbal, como parte de su significado inherente, el movimiento con la manera, y la trayectoria se expresa en un satélite (lenguas de marco satélite):

(1) The ball bounced/rolled down the hall
Mov+manera path (Talmy, 1985, p. 36)

Por otro lado, el español, junto con otras lenguas romances, las lenguas de la familia semítica y las de la familia polinésica, entre otras, funde la trayectoria o path con el movimiento en la forma verbal, y la manera se expresa en una forma léxica independiente (lenguas de marco verbal):

(2) La botella entró a la cueva (flotando)

Mov+path manera (Talmy, 1985, p. 49) 
Ahora bien, con base en estos trabajos pioneros, se han realizado estudios en diferentes lenguas. Las clasificaciones de verbos de movimiento del español que se suelen citar (Dervillez-Batuji, 1982; Lamiroy, 1983, 1991; Cifuentes Honrubia, 1988-1989; Crego García, 2000; Morimoto, 2001; Rohde, 2001) se modelan con base en las tipologías binarias de Talmy y Jackendoff, que fundamentalmente reconocen entre ítems que empaquetan léxicamente el movimiento con la manera (verbos de manera) y los que conjuntan inherentemente el movimiento y la trayectoria o dirección (path).

Así, desde un punto de vista semántico y a pesar de que entre los autores existen diferencias significativas sobre qué verbos pertenecen a qué clase, la mayoría de ellos coinciden en separar los verbos del dominio (dejando aparte los de locación estática, los de movimiento estático o sin traslación, y los de cambio de postura) en dos clases principales: los direccionales y/o de desplazamiento, por un lado, y los de manera del movimiento, por el otro. Los predicados direccionales denotan un movimiento orientado con un punto terminal, mientras que los verbos de manera son no-orientados y atélicos.

Si bien estas propuestas dan cuenta de diferencias significativas en cuanto al comportamiento sintáctico de los verbos de movimiento, son insuficientes para explicar todas las posibilidades construccionales de estos predicados, así como las diferencias semánticas que suscitan la gran gama de construcciones. Como veremos a continuación, el presente trabajo toma como punto de partida una clasificación de verbos de movimiento intransitivos del español que rompe con el espíritu binario de las propuestas de referencia en la bibliografía. Se trata de la clasificación de Ibáñez (2005), la cual, a partir de rasgos aspectuales, distingue tres clases, lo que supone ya un análisis más fino en términos de los componentes semánticos y sintácticos de los predicados de movimiento.

\section{Marco semántico del movimiento; una propuesta ampliada}

El marco conceptual del movimiento que se propone en Ibáñez (2005) se define de la siguiente manera: 
(3) Una entidad Y, que ocupa una posición inicial W, mediante un desplazamiento (D) de determinada forma ( $\alpha$ ), hacia una dirección $(\beta)$, causado por una entidad auto-energética $X$, pasa a ocupar, a través de una ruta específica $R$, un nuevo punto de locación $\mathrm{Z}$, produciéndose un cambio de lugar $(\mathrm{C})$ (versión actualizada de Ibáñez (2005))

Este marco ofrece una visión de un evento de movimiento que contempla los componentes pertinentes para el análisis de la semántica de los verbos que pertenecen a tal dominio. En tanto sustancia conceptual base de la lexicalización de las formas verbales, tales componentes son de tres tipos: por un lado, están las variables externas, representadas por las letras X, Y, Z, W y R, y que, en tanto tales, tienen una manifestación referencial a través de su expresión sintáctica (o morfosintáctica, según la lengua); luego están lo que consideramos variables internas - las letras a y $\beta$ del alfabeto griego, entre paréntesis-, que normalmente son rasgos inherentes lexicalizados, pero con valor variable; $y$, finalmente, encontramos los componentes marcados por letras del alfabeto actual, pero entre paréntesis, $(C)$ y $(D)$, que constituyen rasgos internos inherentes, con un valor invariable o constante, aunque son susceptibles de estar o no lexicalizados por uno $\mathrm{u}$ otro de los predicados del dominio.

Respecto a su identidad semántica, estos componentes pueden dividirse en tres tipos: a) los participantes dinámicos: causante y tema, que respectivamente equivalen a las variables $\mathrm{X}$ y Y; b) los participantes locativos fuente, meta y ruta y locación; y c) los rasgos paramétricos o inherentes: desplazamiento, manera, dirección y cambio de lugar. Siguiendo a Ibáñez (2004), los rasgos paramétricos "son los rasgos que sobre la dimensión en cuestión - el movimiento en este caso- funcionan como los valores distintivos que permiten dar identidad a cada uno de los items que pertenecen a la clase" (Ibáñez, 2004, p. 42).

A continuación veremos en detalle las características semánticas y sintácticas de cada uno de estos componentes que conforman el marco conceptual del movimiento. 


\subsection{Participantes dinámicos: tema y causante}

\subsubsection{El tema}

Todas las expresiones de movimiento codifican una entidad que se desplaza o sufre un cambio de lugar, la cual, desde el trabajo pionero de Gruber ([1965] 1976), recibe el rol semántico de 'tema'. Este participante coincide con la 'figura' de Talmy y la entidad THING de Jackendoff. Es, pues, el principal participante de un evento de movimiento. Además del propio rasgo de movimiento como tal, es el único componente que tiene que estar lingüísticamente implicado (y codificado) en una construcción que denote tal proceso. De acuerdo con Jackendoff (1990), el desplazamiento o cambio de lugar del 'tema' puede ser provocado por una entidad independiente, el 'causante', o puede ser autocausado; en estos casos, el 'tema' es lo que dicho autor llama un selfmover (automovible). Crego García (2000) llama a este tipo de participante entidades auto-energéticas. Típicamente se trata de entidades animadas - humanos y animales - , pero el rol puede ser desempeñado por entidades inanimadas que se desplazan en eventos conceptualmente causados, pero que lingüísticamente se codifican como no-causados - La bala salió disparada con fuerza-. En términos sintácticos, el tema se codifica como sujeto en oraciones intransitivas, como en (4a), y como objeto directo en oraciones transitivas - (4b) - , que implican la presencia de un causante.

\section{(4)a. Robespierre salió del palacio hacia la libertad ${ }^{3}$}

b. Montesquieu trajo su enciclopedia a la reunión

\footnotetext{
${ }^{3}$ Los ejemplos que se usan a lo largo del trabajo con fines tanto ilustrativos como argumentativos son modelados con base en datos de otros estudios realizados mediante el análisis amplio de corpora (cf. Ibáñez, 2005 y Lecumberri, 2011). En sí, este no es un estudio de uso, sino que es un ejercicio argumentativo, en el que se pretende mostrar la presencia de correlaciones semántico-sintácticas a través de pruebas fundamentales como las de sustitución, conmutación y copresencia. Se ha tomado la decisión de mantener los ejemplos lo más simples posibles para hacer la argumentación en pares mínimos más clara y, valga la redundancia, más ejemplar. Se han hecho también búsquedas libres en blogs de internet para constatar la existencia factual de algunas expresiones que funcionan como pruebas lingüísticas de posibilidad estructural, pero que son muy difíciles de constatar en dato de uso de escritura cuidada.
} 


\subsubsection{El causante}

El causante es el participante que provoca el movimiento del tema. En español, como en muchas otras lenguas, podemos encontrar verbos de movimiento inherentemente causativos, que siempre requieren de causante y tema - (5a) - ; verbos causativos que permiten una alternancia reflexiva que proyecta el movimiento como auto-causado - (5b) - ; y verbos no-causativos que no permiten codificar un causante distinto del tema, como se ejemplifica en $(5 c)$.

(5)a. Juan llevó a María a la casa ${ }^{*}$ Juan llevó a la casa ${ }^{*}$ Juan se llevó a la casa (a sí mismo)

b. Juan metió el libro en el cajón / Juan se metió a la casa

c. Juan entró a la casa / Juan entró la carta a la casa

Como se desprende de oraciones como las de (5c), aunque en el marco conceptual se concibe el movimiento como un evento inherentemente causativo, la causa no siempre está lexicalizada en los predicados bajo estudio.

Es importante mencionar, en consonancia con lo mencionado por Crego García (2000), que no todas las oraciones transitivas con verbos de movimiento son causativas:

(6)a. Frodo caminó media cuadra hasta el callejón

b. Sam anduvo toda la senda hasta la montaña

En las oraciones de (6), el sujeto es un tema selfmover, mientras que el objeto directo es una especie de ruta sobre el cual el tema se desplaza. No se codifica un causante adicional al tema y por lo tanto las oraciones no son causativas, aunque sí transitivas. Las oraciones transitivas-causativas se pueden parafrasear con la forma 'X causó que $\mathrm{Y}$ ', donde $\mathrm{X}$ es el causante y $\mathrm{Y}$ es el evento de movimiento, tal y como se muestra en la proposición entre paréntesis de (7a). Por su parte, las oraciones transitivas-no causativas no permiten dicha paráfrasis - (7b) -

(7)a. Rubén llevó a José a Egipto ('Rubén causó que José pasara a estar en Egipto') 
b. Benjamín recorrió la calle ( ${ }^{*}$ Benjamín causó que la calle estuviera recorrida')

\subsection{Los participantes locativos}

Todas las expresiones con verbos de movimiento requieren conceptualmente de participantes locativos para completar el estado de cosas denotado por el predicado, aunque no siempre se codifiquen explícitamente en las oraciones correspondientes. Estos participantes, que aquí llamamos de forma genérica 'locativos', están relacionados con el fondo o landmark de Talmy, así como con las funciones PLACE y PATH de Jackendoff. Generalmente su referente es un lugar o un objeto concreto inanimado que delimita la acción del verbo, el cual se codifica, principalmente, en una lengua como el español, mediante una frase preposicional, como en (8a), aunque también puede proyectarse, como en el caso de los locativos del tipo ruta, como sujeto u objeto directo, según se puede ver en los ejemplos $(8 b)$ y $(8 c)$, respectivamente.

(8)a. Fabricio camina a la casa / por la calle

b. El camino conduce a la ciudad

c. Federico subió las escaleras

A diferencia de las propuestas antes mencionadas, en el presente trabajo se distingue de forma específica seis tipos de locativos o fondos: fuente, ruta, meta, punto de referencia, locación-ruta y trayectoria. Desde Gruber ([1965] 1976), los tres primeros son usados de forma recurrente en la bibliografía. El punto de referencia y la locación-ruta son nociones que aquí introducimos para dar cuenta de los tipos de ruta asociados a predicados puntuales (por ejemplo, en María cruzó la frontera) y a predicados atélicos y durativos (por ejemplo, en Anduve todo el día en la calle), respectivamente; el sexto tipo, la trayectoria, supone desplazamientos completos de punto a punto. Sus características definitorias se señalan más abajo.

La distinción formal de estas seis categorías se debe a que, como se verá más adelante en la clasificación de predicados, los 
distintos verbos de movimiento especializan su significado a partir del foco semántico que tienen en uno o varios de estos locativos, lo que se puede ver a partir de su combinabilidad con cada uno de ellos. En el esquema conceptual expuesto arriba en (3), estas funciones locativas constituyen variables cuyo requerimiento está lexicalizado de forma específica por cada predicado del dominio, y su valor referencial tiene que ser expresado sintácticamente para completar en una oración el significado inherente del núcleo verbal.

De estos participantes locativos, el que aquí llamamos 'locación’ es el locativo más básico y conceptualmente más simple ya que refiere a un espacio que puede relacionarse tanto con eventos estativos - (9a) - como dinámicos - (9b) - en términos de Jackendoff (1983). Su codificación más común en español es como una frase preposicional introducida mediante la preposición en.

(9)a. El libro está en la mesa

b. Parménides anda en el camino pregonando la verdad

En (9a) se ejemplifica un evento de locación estativa, que en español típicamente se construye con el verbo estar y con un complemento introducido por la preposición en, con el rol de 'locación' En este trabajo, nos encargamos solo del análisis de eventos dinámicos, por lo que dejamos de lado cualquier otra consideración sobre esta clase de locativo.

Por otro lado, como se ejemplifica en (9b), algunos verbos de actividad, tales como andar, transitar, pasear, etc., suelen aparecer (en datos de uso) también con complementos introducidos por en. A diferencia de su papel con verbos estativos, estas locaciones desempeñan con predicados como andar más bien una función similar a la de 'ruta', como se puede ver en la paráfrasis de (9b) Parménides anda por el camino pregonando la verdad; en estos casos la locación tiene un significado dinámico que propiamente lo separa de la 'locación estativa', como la del ejemplo (9a), pues denota el espacio por el cual se lleva a cabo un desplazamiento. En este sentido, es conveniente identificarlo 
como una función locativa distinta y proponemos denominarla 'locación-ruta'. Más adelante mostramos que se trata de un tipo de ruta que complementa solo a cierto tipo de verbos de actividad.

Es muy importante señalar que como tal la locación-ruta es distinta a una 'locación-escenario', o setting, que más que ser el espacio por el cual se desplaza el tema, constituye un tipo de complemento que enmarca el evento denotado por el verbo núcleo, como en (10a):

(10)a. Alicia pintó un cuadro en el parque

b. Estando en el parque, Alicia pintó un cuadro

c. ?? Parménides anda estando en el camino

Como muestra la paráfrasis en (10b), los 'locativos-escenarios' son esencialmente predicados de un nivel superior al de la oración que modifican (Helbig, 1971; Van Valin y LaPolla, 1997), por ello pueden ser parafraseados en forma de cláusulas. Son complementos circunstanciales no regidos por la semántica verbal. Como muestra (10c), paráfrasis de (9b), esto último no es posible con las 'locaciones-ruta'; en este caso, se trata de un complemento que expresa parte del valor semántico lexicalizado por el predicado.

En lo que respecta a los locativos fuente, ruta y meta, se trata de categorías que se relacionan únicamente con eventos dinámicos de movimiento, pues tienen la función específica, dentro del marco conceptual, de indicar, respectivamente, el inicio, el proceso y el final del evento.

La fuente es relativa al punto inicial del movimiento. El tema se encuentra en reposo en un espacio previo al desplazamiento denotado por el verbo $y$, a medida que se desplaza, se aleja de dicho punto. En español se codifica como una frase preposicional introducida con de o desde.

\section{(11)a. Martín salió de la casa}

b. María Elena fue desde su casa hasta la escuela

Como mostramos más adelante, se trata de un participante que es regido por los predicados que en su semántica lexicalizan 
la fase de inicio de un desplazamiento, tales como salir o partir, aunque también puede aparecer, como en (11b), en construcciones en donde se perfila un desplazamiento de punto a punto.

La meta, por su parte, constituye el punto final o punto de arribo del tema. Se trata de un participante regido por verbos que lexicalizan la fase terminal del movimiento o que denotan un movimiento de punto a punto. En español, se codifica a través de una frase preposicional introducida por las preposiciones a o hasta, como en (12).

\section{(12)a. Adalberto fue a su casa}

\section{b. Escipión siguió hasta el final del camino}

Entre los ítems que rigen este tipo de participante están los verbos durativos del tipo de ir, venir, subir, regresar, que denotan un desplazamiento de punto a punto, o los predicados puntuales del tipo de llegar y entrar, que perfilan una fase terminal del movimiento.

Como hemos señalado, pues, la fuente y la meta se relacionan con los puntos límites del movimiento y presentan muy poca variación en la selección de las preposiciones que las introducen: como vimos, de y desde para la 'fuente', y a, hasta y en para la 'meta'.

La ruta, por su parte, es el locativo que presenta la semántica y sintaxis más elaborada y compleja (cf. Lecumberri, 2011), pese a ser el menos estudiado. Se puede definir como el espacio o camino por el cual el tema se mueve; es el locativo vinculado con el proceso interno y durativo del movimiento, más específicamente, con el desplazamiento. Se codifica de forma más frecuente como un complemento preposicional introducido con por como en (13a), aunque también puede introducirse con otras preposiciones como a través de, sobre y a lo largo de, como en (13b), cada una de las cuales aporta, a partir de distintos ma-

\footnotetext{
${ }^{4}$ Las implicaciones semánticas derivadas de la alternancia de las preposiciones de y desde para fuente, y a y hacia para meta es un fenómeno que queda fuera del alcance del presente trabajo.
} 
tices semánticos, un significado más especializado sobre la relación entre el predicado, el tema y el locativo.

(13)a. Bonifaz caminaba por la orilla de un río jaspeado de luces y de sombras

b. Juan Miguel circulaba sobre / a lo largo de el camino central del campus

Un aspecto sintáctico poco estudiado de las rutas es su posibilidad, con algunos verbos, de aparecer codificadas como sujeto oracional $-(14 \mathrm{a})$ - , o como objeto directo - (14b) hecho que puede ser un indicio de su valor propiamente argumental con tales predicados, estatus que normalmente no se les otorga.

(14)a. El camino avanza de norte a sur

b. El convoy circuló toda la avenida

Como veremos más adelante, las 'rutas' son regidas semánticamente por los verbos que denotan un movimiento de punto a punto, como ir y venir, y por los predicados de actividad atélicos que solo implican el proceso intermedio del desplazamiento, como andar y seguir.

La noción de locativo de 'punto de referencia', categoría que introducimos en este trabajo por primera vez, se refiere a un espacio locativo que delinea el movimiento, pero no como camino de un desplazamiento, sino solo como un 'punto de cruce'. Se trata de un tipo de locativo que se codifica principalmente como objeto directo (15a), aunque también puede ser introducido con la preposición por (15b):

\section{(15)a. El hombre cruzó la frontera}

b. El hombre pasó por la iglesia (i. e. cruzó la iglesia, o la iglesia es un punto de cruce)

El punto distintivo de su identidad, y la importancia de reconocerlo como uno de los tipos de locativos, radica en que su 
codificación es propia únicamente de los verbos puntuales de cambio de locación, y no aparece con verbos que inherentemente implican un desplazamiento, y por lo mismo son durativos.

Finalmente, introducimos aquí también la noción de 'trayectoria' como un tipo específico de locativo, con un valor distinto al que típicamente se le ha otorgado en la bibliografía, en la que solo es una traducción inespecífica del concepto igualmente nebuloso de path. Por trayectoria en este trabajo entendemos el tipo de locativo que se codifica como objeto directo con predicados que implican un desplazamiento de punto a punto, como en los ejemplos de (16), que como veremos más adelante, incluimos en el grupo de los verbos de realización:

\section{(16)a. Rosaura recorrió la ciudad \\ b. Juan subió la montaña}

Los objetos directos de los ejemplos de (16) semánticamente sintetizan la referencia a un punto de partida, a un desplazamiento y a una meta; así, subir la montaña implica 'ir desde abajo hasta arriba, recorriendo la montaña como camino' La trayectoria, pues, semánticamente sintetiza fuente, ruta y meta.

\subsection{Rasgos paramétricos}

Los rasgos paramétricos o inherentes funcionan como los rasgos distintivos de base mediante los cuales los diversos verbos se distinguen en términos paradigmáticos. Corresponden a las variables internas y las constantes del esquema conceptual en (3). Frente a las propuestas menos detalladas previamente revisadas, que consideran solo el rasgo genérico de movimiento, además del de manera, en el presente trabajo consideramos como rasgos paradigmáticos distintivos, por un lado, el movimiento, el desplazamiento y el cambio de lugar, que son constantes, pero susceptibles o no de ser lexicalizados; y, por el otro, la manera y la dirección, que son variables internas que pueden ocurrir lexicalizadas en el verbo con valor variable, o pueden proyectarse como modificadores sintácticos independientes. A continuación 
mostramos la pertinencia semántico-sintáctica de cada uno de estos rasgos para la clasificación de los predicados estudiados.

\subsubsection{Movimiento y desplazamiento}

El movimiento y el desplazamiento representan dos componentes que se pueden confundir con facilidad debido a su similitud semántica. De hecho, en español, al igual que en otras lenguas, es muy común que estos dos elementos efectivamente se fusionen en el verbo, por lo que pueden ser conceptualizados como un mismo componente. En (17a) tenemos un verbo que lexicaliza ambos rasgos: ir efectivamente implica que el movimiento se da en la forma de un desplazamiento. Sin embargo, podemos decir que el movimiento es un componente más básico que el desplazamiento, en cuanto que este siempre implica movimiento, pero el movimiento no necesariamente implica un desplazamiento; así, en (17b) el núcleo verbal lexicaliza el movimiento y la manera, pero no el desplazamiento; girar, en este sentido, supone un movimiento "estático" no translacional.

\section{(17)a. Otón fue al palacio}

b. La tierra gira (sobre su eje)

También los verbos de 'cambio de posición', tales como sentarse o voltearse, implican movimiento, pero no desplazamiento. Hay que tener en cuenta, pues, que movimiento y desplazamiento son componentes semánticos muy relacionados, pero, a fin de cuentas, distintos. Es importante notar, incluso, que el desplazamiento tampoco está lexicalizado en predicados dinámicos pero que aspectualmente son puntuales y solo implican un cambio de lugar, tales como entrar o llegar, que en la mayoría de las clasificaciones binarias son equivocadamente, creemos, agrupados en la clase de los verbos de desplazamiento o direccionales.

Como veremos, el desplazamiento es un rasgo propiamente lexicalizado por los predicados que implican un movimiento de punto a punto, o por los que siendo atélicos focalizan la parte intermedia del proceso, justamente el desplazamiento, tales como caminar, andar o deambular. 


\subsubsection{Manera}

Este rasgo se refiere a la forma o modo en el que el tema se mueve, independientemente de si hay desplazamiento o no. Como señalamos arriba, justamente, girar en (17b) es un ejemplo claro de un verbo que lexicaliza la manera y el movimiento, pero no el desplazamiento. La manera, pues, es también un rasgo lógicamente independiente. Como mencionamos anteriormente, su presencia en ausencia de trayectoria o path, es uno de los componentes fundamentales de la tipología de Talmy. En una mirada más cercana, sin embargo, dentro de la noción genérica de 'manera', en este trabajo proponemos que se pueden distinguir varios subtipos de la misma, como rasgos paradigmáticos distintivos: a) la manera en que se mueve la figura, en ausencia de desplazamiento, como en bailar y girar; b) la manera en que se mueve la figura al desplazarse, como en caminar, trotar y arrastrarse; c) la manera, no del movimiento de la figura, sino propiamente del desplazamiento mismo, como en merodear o rondar; y d) la manera del movimiento relativa al tipo del fondo, como con predicados del tipo de nadar y volar.

El español cuenta con verbos en los que la manera está lexicalizada en el predicado - (18a) —, aunque generalmente esta se expresa a través de un formante léxico independiente al verbo principal, como en (18b):

\section{(18)a. Eleonor camina / corre / se desliza hasta su casa \\ b. Fátima entró a su casa corriendo / tropezando / rodando}

Como se vio anteriormente, Talmy (1985) clasifica las lenguas a partir de si lexicalizan el path o la manera en el verbo. En español, lengua generalmente clasificada como de marco verbal, podemos encontrar un grupo relativamente amplio de predicados que lexicalizan únicamente el desplazamiento y no la manera (ir, venir, regresar); algunos que implican la manera, aunque no el 'desplazamiento' (girar); y otros que fusionan ambos elementos (rodar, caminar).

Ahora bien, aunque sí es recurrente en términos tipológicos la existencia de los dos patrones polares de lexicalización en 
los que, por un lado, son el desplazamiento y la manera los que se funden en la denotación verbal, y, por el otro, son los componentes de movimiento y/o desplazamiento los que se lexicalizan juntos con el rasgo de path (en términos de Talmy), manera y path no son ni lógica ni lingüísticamente excluyentes, como lo muestra el hecho de que verbos que típicamente implican 'manera', como caminar, pueden aparecen en construcciones télicas con complementos de meta (Roldán caminó a la casa), o que existan incluso algunos verbos puntuales, que no lexicalizan desplazamiento, pero que sí implican manera, como saltar.

Como mostramos en el apartado 3, además de reconocer distintos subtipos de 'maneras', lo importante para nuestra clasificación es que el rasgo es independiente de la presencia o no de desplazamiento.

\subsubsection{Dirección}

En el presente trabajo el concepto de 'dirección' se distingue formalmente de los componentes de meta o punto de arribo y de cambio de lugar, aunque los tres suelen aparecer lexicalizados juntos, y en consecuencia no son reconocidos como lógica y lingüísticamente independientes en la bibliografía. En la misma tipología de Talmy los tres rasgos se presentan mezclados o no analizados bajo la categoría de path, lo que en nuestra perspectiva representa una posible fuente de confusiones en el análisis. Por ejemplo, podemos encontrar verbos que lexicalizan la dirección, el cambio de lugar y el requerimiento de una meta, como entrar en (19a), o únicamente dirección, sin 'cambio de lugar' (y sin meta, por lo tanto), como dirigirse en (19b) y avanzar en (19c). La presencia de cambio de lugar, por el contrario, siempre va acompañada del requerimiento de fuente o meta, o de ambas.

(19)a. El perrito entró a la casa $\rightarrow$ implica que 'El perro ya está dentro de la casa'

b. El perrito se dirigió hacia la casa $\rightarrow$ NO implica que 'El perro ya está en la casa'

c. El perrito avanza en el parque $\rightarrow$ NO implica que 'ha pasado a estar en el parque' 
La dirección se entiende aquí de dos maneras distintas: en primer lugar, en un sentido amplio, como la orientación del movimiento en relación con un locativo. Sin embargo, como ya se mencionó, frente a la mayoría de los autores que funden la idea de dirección con la de punto de arribo, en este trabajo distinguimos entre la meta como tal y la dirección propiamente, que no necesariamente marca el punto final del movimiento, en el sentido de que indica orientación y no necesariamente terminación del movimiento. Así, en el ejemplo (20a), los complementos en negritas señalan la orientación del desplazamiento, pero no implican la terminación del mismo, como lo indica la posibilidad de agregar la especificación pero nunca llegó; (20b) por su parte, muestra que el punto de llegada y la dirección pueden codificarse en sintagmas independientes; (20c), a su vez, muestra que meta y dirección no son categorías mutuamente implicadas: un verbo puede lexicalizar la dirección-avanzar inherentemente implica 'hacia adelante' - y no ser compatible con complementos de meta.

(20)a. Robespierre caminó hacia la casa / en dirección a la casa, pero nunca llegó

b. María Luisa camina a su casa en dirección al norte

c. ??Atahualpa avanzó a la casa

El segundo sentido de dirección se refiere justamente al rasgo lexicalizado en ítems como avanzar ('hacia adelante') y retroceder ('hacia atrás'), y subir ('hacia arriba') y bajar ('hacia abajo'), que manifiestan la orientación del movimiento en los dos ejes de un plano cartesiano (horizontal y vertical), ya sea que se implique o no la presencia de un punto terminal de arribo.

Entonces, aunque en algunas ocasiones la dirección se confunde con la meta, debido a que tienen mucha compatibilidad semántica y a que en muchas ocasiones ambos componentes se funden en un solo participante, es importarte estudiar estos dos componentes de manera separada, ya que son lógica y lingüísticamente distintos. 


\subsubsection{Cambio de lugar}

Este rasgo no es identificado de forma específica en las propuestas existentes en la bibliografía. Se trata, sin embargo, de un rasgo importante que se relaciona con la telicidad de los predicados, aunque, justamente, no sean lo mismo. Por un lado, permite distinguir entre aquellos verbos que pertenecen a las clases aspectuales (Dowty, 1979; Van Valin, 1993) de los logros —(21a) - y las realizaciones —-(21b) —, que sí lexicalizan un cambio de locación, y aquellos que pertenecen al grupo de las actividades, y que únicamente lexicalizan el desplazamiento, sin un final inherente, como (21c). Por otro, se trata de un rasgo que permite diferenciar entre verbos del tipo de (21a) y (21b), que implican un telos y un cambio de lugar, y verbos que son inherentemente télicos, pero que no necesariamente implican un cambio de lugar, como (21d), en el cual no se implica que 'el emperador pase a estar en un lugar en el que no estaba. ${ }^{5}$

\section{(21)a. Llegamos a su casa}

b. Martina fue a la tienda

c. María Antonieta deambula por los pasillos

d. El emperador recorrió la ciudad

A manera de resumen de lo expuesto hasta aquí, presentamos el cuadro 1 con las correspondencias entre las categorías de Talmy y Jackendoff, y las que aquí se han expuesto:

\begin{tabular}{|l|l|l|}
\hline Talmy & Jackendoff & Propuesta de este trabajo \\
\hline Movimiento & EVENT & Movimiento \\
\hline Movimiento & EVENT + PATH & Desplazamiento \\
\hline & & Cambio de lugar \\
\hline Path & PATH & Dirección \\
\hline Manera & & Manera de la figura \\
\hline Manera & & Manera del desplazamiento \\
\hline Figura & THING & Tema \\
\hline Causa & & Causa \\
\hline
\end{tabular}

\footnotetext{
${ }^{5}$ Sin embargo, la posibilidad de una expresión como La ciudad ya está recorrida pone de manifiesto la telicidad del evento.
} 


\begin{tabular}{|c|c|c|}
\hline $\begin{array}{l}\text { Fondo (Ground) / } \\
\text { Path }\end{array}$ & PATH & Fuente \\
\hline $\begin{array}{l}\text { Fondo (Ground) I } \\
\text { Path }\end{array}$ & PATH & Meta \\
\hline \multirow[t]{4}{*}{$\begin{array}{l}\text { Fondo (Ground) / } \\
\text { Path }\end{array}$} & PATH & Ruta \\
\hline & & Punto de referencia \\
\hline & & Locación-ruta \\
\hline & & Trayectoria \\
\hline
\end{tabular}

Cuadro 1. Correspondencia entre los formantes y rasgos de análisis de este trabajo y los propuestos por Jakendoff y Talmy

\section{Propuesta para una nueva clasificación de los verbos de movimiento en español}

Como punto de partida para la presente clasificación tomamos como base la propuesta tripartita de Ibáñez (2005). Esta parte de los rasgos aspectuales de los predicados y los divide en tres grupos: realizaciones, logros y actividades; como mostramos abajo, esta clasificación permite la inclusión en el análisis de componentes y rasgos más finos que hemos presentado en el apartado anterior. A continuación se presenta una breve caracterización de esta clasificación tripartita:

1. Verbos de realización. Denotan un desplazamiento de punto a punto - (22a) - , es decir, perfilan el marco completo del movimiento: la fase de partida del punto inicial $\mathrm{W}$, el desplazamiento y el arribo final al punto $Z$. Tienen duración interna, correlacionada con el desplazamiento, como se muestra en (22b), y son télicos, en función de que implican un punto terminal, lo mismo que un cambio de lugar, según se desprende de la posibilidad de la construcción resultativa de un ítem como regresar - (22c) - . Se incluyen aquí verbos como ir, venir, subir, bajar, regresar, etc.

(22)a. Juan regresó de la escuela a la casa

b. Juan está regresando de la escuela (está realizando el proceso de 'regresar') 


\section{c. Juan está recién regresado a la casa ${ }^{6}$}

2. Verbos de logro. Denotan un cambio de lugar con referencia a un punto de arribo, una meta, o con referencia a un punto de inicio del movimiento, esto es, una fuente; son, por tanto, télicos - (23a) - . Además, se trata de procesos sin duración interna, es decir, son puntuales, por eso implican un significado 'especial' en la construcción progresiva, como se puede ver en (23b); $y$, como muestra (23c), denotan como resultado un cambio de lugar. Predicados de esta clase son algunos como entrar, salir, llegar y partir.

(23)a. Juan salió de la casa

b. Juan está saliendo de la casa (aún no realiza el proceso de 'salir')

c. Juan está recién salido de su casa

3. Verbos de actividad. Perfilan únicamente la fase de desplazamiento de la estructura conceptual del movimiento, por lo que el evento es durativo, de ahí que la construcción progresiva - (24b) - sí suponga la realización del evento en curso; igualmente, el evento no está delimitado, es decir, es atélico, y por ello no requiere de locativos télicos - (24a)-. Por su parte, (24c) es agramatical en la medida de que correr es inherentemente un verbo indelimitado, que no supone cambio de lugar. Verbos de este tipo son andar, avanzar, transitar, correr, caminar, arrastrarse, cojear, etc.

(24)a. Juan corre todas las mañanas en el parque

b. Juan está corriendo en el parque

c. *Juan está recién corrido en el parque

\footnotetext{
${ }^{6}$ Este tipo de construcción, igual que la lilustrada en (26c), no es común en muchos dialectos del español, pero una búsqueda libre en internet muestra que existen ocurrencias de uso reales. En todo caso, semánticamente, Juan regresó a la casa implica que 'Juan está ahora en la casa', lo mismo que Juan salió de la casa implica que 'Juan ya NO está en la casa'. Para las búsquedas de internet mencionadas, solo se constató que al poner una de las frases en el 'buscador', por ejemplo, está regresado, se ofrecieran resultados.
} 
Esta clasificación, pensamos, ofrece una caracterización adecuada del comportamiento básico de los lexemas relacionados con el dominio del movimiento; sin embargo, un análisis más detenido permite ver que predicados que pertenecen a una misma clase aspectual pueden lexicalizar distintos componentes del marco conceptual y, por tanto, a su vez, pueden presentar distintos comportamientos sintácticos. En razón de esto, consideramos necesario hacer una clasificación aún más detallada, tomando en cuenta los componentes específicos del marco conceptual que los diferentes verbos lexicalizan. Para esta nueva clasificación, además de los componentes ya apuntalados en el apartado anterior, se agregan los rasgos aspectuales de la clasificación de Ibáñez (2005), básicamente la telicidad y la puntualidad. Por razones de espacio, queda fuera del análisis lo relativo a la presencia o no del rasgo de 'causa'. Se consideran aquí, entonces, solo los componentes concernientes a los predicados intransitivos de movimiento.

\begin{tabular}{|l|l|l|l|l|l|l|l|l|l|l|l|l|l|l|}
\hline Verbo & Mov & Desp & $\mathrm{CL}$ & Dire & Man & Telic & Punt & Tem & Fuen & Meta & Ruta & PR & LRu & Tray \\
\hline Realizaciones & + & + & + & $+/-$ & $+/-$ & + & - & + & + & + & + & - & - & + \\
\hline Logros & + & - & + & $+/-$ & - & + & + & + & + & + & - & + & - & - \\
\hline Actividades & + & + & - & $+/-$ & $+/-$ & - & - & + & - & - & + & - & $+/-$ & - \\
\hline
\end{tabular}

Cuadro 2. Rasgos semánticos de los predicados de movimiento ${ }^{7}$

En el cuadro 2 podemos ver los rasgos que presentan los tres grupos primarios, que se corresponden con la clasificación de Ibáñez (2005) ejemplificada en (22), (23) y (24). El signo (+/-) indica que el rasgo puede o no presentarse, según el tipo de verbo específico, pero que justamente por eso es relevante para las subclasificaciones que en adelante presentamos. En los siguientes apartados se hace una revisión detallada de cada uno de estos tres grupos para mostrar las diferencias internas en cada uno de ellos que nos permiten establecer subclases relevantes semántica y sintácticamente.

\footnotetext{
${ }^{7}$ Las abreviaturas de la tabla están por las siguientes categorías de rasgos: Mov = movimiento; Desp = desplazamiento; $\mathrm{CL}$ = cambio de lugar; Dire = dirección; Man $=$ manera; Telic $=$ telicidad Punt $=$ puntualidad; Tem = tema; Fuen = fuente; Meta = meta; Ruta = ruta; $\mathrm{PR}=$ punto de referencia; $\mathrm{LRu}=$ locación-ruta; Tray = trayectoria.
} 
3.1 Subclases de los verbos de movimiento de realización

Estos verbos han sido divididos en dos subgrupos, según sus diferencias internas:

\subsubsection{Realizaciones estricto sensu}

Este subgrupo está formado por predicados que en las clasificaciones más típicas se conocen como de desplazamiento o direccionales. Se trata de ir, venir, regresar, volver, trasladarse, subir, bajar, ascender, descender, trepar, escalar, encaminarse, retornar y acudir, entre otros.

Además de los rasgos aspectuales de telicidad y duratividad, lexicalizan los rasgos de desplazamiento, cambio de lugar y dirección. Típicamente, no implican inherentemente la manera del movimiento. En términos sintácticos, pueden expresar complementos de fuente - (25b) - , meta - (25c) - y ruta - (25d) - , que pueden aparecer proyectados simultáneamente, como en (25a), aunque comúnmente, por razones pragmáticas, solo se exprese uno de los locativos.

(25)a. Martina fue de su casa a la tienda de discos por la ruta corta

b. Julián regresó de las montañas, donde vacacionaba

c. Ramiro se trasladó al bar en taxi

d. Ruth descendió por el camino viejo

De forma opuesta a ítems de otras de las subclases aquí postuladas, las realizaciones de movimiento no se construyen con complementos de punto de referencia; así, en (26a) el complemento por el parque se interpreta como el camino por el cual se lleva a cabo el desplazamiento y no solo un punto de referencia o de cruce. Tampoco aparecen las realizaciones con locacionesruta, como se ve en (26b) y (26c).

(26)a. ??Mauricio fue a su casa por el parque (en el sentido de punto de referencia)

b. ${ }^{\star}$ Fabiola vino en el parque

c. ${ }^{\star}$ Domingo subió en la montaña 
En el cuadro 3 se presentan los rasgos o componentes que inherentemente forman parte de este tipo de realizaciones:

\begin{tabular}{|l|l|l|l|l|l|l|l|l|l|l|l|l|l|l|}
\hline Clase & Mov & Desp & CL & Dire & Man & Telic & Punt & Tem & Fuen & Meta & Ruta & PR & LRu & Tray \\
\hline Realiza I & + & + & + & + & $-1+$ & + & - & + & + & + & + & - & - & + \\
\hline
\end{tabular}

Cuadro 3. Rasgos semánticos de las realizaciones stricto sensu

Los predicados que pertenecen a este subgrupo en general implican la dirección como una orientación general del movimiento desde un punto de inicio hacia un punto terminal. Adicionalmente, varios de ellos también lexicalizan una dirección específica en términos de los ejes de un plano cartesiano. Así, subir, ascender, escalar y trepar suponen que el desplazamiento es 'hacia arriba'; por su parte, bajar y descender implican un movimiento 'hacia abajo. Otros ítems toman como dirección del desplazamiento el punto deíctico de enunciación; tal es el caso de venir, regresar, volver y retornar, que inherentemente implican que el desplazamiento del tema es hacia el hablante.

La presencia conjunta de los rasgos de dirección y desplazamiento permite que este tipo de predicados tengan también la posibilidad de construirse con complementos direccionales introducidos por hacia o para - (27a) y (27b)—, comportamiento que puede resultar extraño con algunos verbos de logro (al menos los de meta), que también lexicalizan la dirección, pero que son puntuales - $(27 \mathrm{c})$ y $(27 \mathrm{~d})-$ :

\section{(27)a. Lotario se encaminó para el bosque \\ b. Claudio retornó hacia el palacio \\ c. ?? Francisco Fernando entró para la sala del trono \\ d. ??Carlos llegó hacia la batalla}

Como ya se mencionó, la manera del movimiento es un rasgo que típicamente no es lexicalizado por este tipo de predicados en las lenguas del mundo. Sin embargo, no hay propiamente ninguna oposición conceptual o lingüística per se para su combinación con los componentes de telicidad, cambio de lugar y dirección, como lo demuestra la existencia de ítems como escalar y trepar, que además de especificar rasgos referenciales 
acerca de la meta, inherentemente implican la forma en que se lleva a cabo el desplazamiento; así lo deja ver la definición que el diccionario de la RAE da para trepar: "Subir a un lugar alto o poco accesible valiéndose y ayudándose de los pies y las manos" (DLE: consulta en línea, 11 de julio de 2018). Los patrones tipológicos de lexicalización que separan la 'manera' de la 'dirección + cambio de lugar' no son, pues, sino una tendencia, pero no un requerimiento estructural.

Ahora bien, en consonancia con lo anterior, además de los verbos que léxicamente pertenecen a esta clase, hay que considerar aquí también las construcciones télicas que pueden proyectar algunos verbos que de base son actividades, y atélicos, por lo tanto, como caminar, correr, rodar, arrastrarse y deslizarse, entre otros, que sí implican la manera del desplazamiento:

(28)a. Rogelio camina todos los días una hora

a. Rogelio caminó hasta el gimnasio

b. Joaquín se arrastra porque no puede caminar

b. Joaquín se arrastró a la cantina

Como se muestra en los ejemplos no-prima de (28), estos predicados se pueden utilizar, y este es su uso más frecuente en datos de corpus (Ibáñez, 2005), como procesos indelimitados sin la presencia de complementos de fuente o de meta. Sin embargo, los ejemplos prima dejan ver que no hay nada que impida su construcción con complementos de meta (o fuente), lo que efectivamente transforma su identidad aspectual, convirtiéndolos en eventos télicos. Se trata de un proceso muy reconocido en la bibliografía (Van Valin y LaPolla, 1997; Ibáñez, 2005; Gutiérrez, 2016), y común a muchas lenguas, que implica una derivación léxica sistemática de verbos de actividad a verbos de realización. Este proceso no es exclusivo de predicados de la clase del movimiento, sino que es común también a otro tipo de verbos, como los de 'creación' y 'consumo' (Van Valin y LaPolla, 1997). Se trata, pues, de ítems que pertenecen a dos clases distintas, según el tipo de construcción en la que aparecen.

Un rasgo sintáctico que comparten algunas de las realizaciones de base - subir, bajar, ascender, descender, trepar y esca- 
lar- y algunas de las derivadas - caminar, correr, rodar, nadar, serpentear y reptar - es el hecho de que pueden proyectar un participante locativo codificado como objeto directo:

(29)a. Ulises trepó rápidamente al árbol

a. Ulises trepó el árbol rápidamente

b. Maricarmen caminó por el parque

b. Maricarmen caminó el parque completo

En los ejemplos no-prima de (29) la locación está codificada como complemento preposicional, mientras que en las oraciones prima esta aparece como objeto directo. Así, la locación de (29a'), el árbol, por ejemplo, puede ser clitizada con un pronombre acusativo: Ulises lo trepó rápidamente. Es interesante notar que el tipo de predicado determina la función semántica del objeto directo: con los verbos que son realizaciones de base, como trepar, se trata de la trayectoria completa de punto a punto; el árbol en (29a') es al mismo tiempo fuente, ruta y meta; por su parte, con los ítems que son realizaciones derivadas, como con caminar, el objeto directo es la ruta. Así, Subir el árbol implica 'quedar arriba del árbol', pero Caminar el parque no implica estar en una meta específica. Esto es un indicador claro de su adscripción de base como actividades, pues como tales focalizan primordialmente solo la fase intermedia de desplazamiento y por ello delinean una ruta como parte de su estructura argumental. De hecho, como veremos más adelante, aquí postulamos que las construcciones transitivas de los verbos de actividad pertenecen a la segunda subclase de las realizaciones de movimiento (ver apartado siguiente).

Ahora bien, hay que señalar que las de (29) son construcciones transitivas pero no causativas; ${ }^{8}$ Ulises trepó el árbol, no puede leerse como '*Ulises causó que el árbol quedara arriba. ${ }^{9}$

\footnotetext{
${ }^{8}$ Algunos de los verbos de la clase se instancian también en construcciones transitivas propiamente causativas. Por ejemplo, Etelvina subió la maleta a la cama sí implica que 'Etelvina causó que la maleta quedará en la cama'.

${ }^{9}$ Tampoco se puede interpretar de Ulises trepó el árbol que 'Ulises se causó a sí mismo que quedara arriba del árbol'. El 'auto-movimiento' puede considerarse concep-
} 
Hay que indicar también, con relación a estas construcciones transitivas, que a pesar de que codifican un locativo como objeto directo, tienen su foco resultativo en el tema codificado como sujeto; así, Ulises trepó el árbol, implica que 'Ulises está trepado en el árbol' y no que ‘*el árbol está trepado'. Según iremos viendo en lo subsiguiente, este comportamiento de las realizaciones de movimiento es un rasgo sintáctico diferencial a notar entre varias de las subclases postuladas en este trabajo.

\subsubsection{Realizaciones sin cambio de lugar y sin dirección}

El único ítem que pertenece de base a este grupo es recorrer. Como lo indica el título de la subclase misma, se trata de un verbo que denota una realización; es télico y durativo por lo tanto, pero, de forma muy interesante y muy poco común, no lexicaliza el cambio de lugar, como se sigue del hecho de que las oraciones no-primas de (30) no impliquen las proposiciones de los ejemplos prima; recorrer no denota que el tema pase a estar en un nuevo lugar.

(30)a. Maritza recorrió la ciudad completamente

a. *'Maritza no estaba en la ciudad y ha pasado a estar en ella'

b. Georgina recorrió el río en lancha

b. *`Georgina no estaba en el río y ha pasado a estar en él’

Como se puede observar en (30), una característica diferencial importante de recorrer, frente al grupo de las realizaciones stricto sensu, es que solamente se proyecta en construcciones transitivas; esto es, el complemento de trayectoria (que sintetiza fuente, ruta y meta) solo se codifica como objeto directo y no puede aparecer alternativamente proyectado como complemento preposicional, sin importar su identidad semántica como ruta $-(31 a)$ - fuente $-(31 b)$ - , meta $-(31 c)$ - o fuente-meta $-(31 d)-$ :

tualmente como una forma de causatividad, pero lingüísticamente hablando no lo es. Como lo señalan Van Valin y Lapolla (1997), las expresiones causativas deben tener un causante diferenciado del tema o paciente. 
(31)a. ${ }^{\star}$ Marina recorrió por la ciudad

b. ${ }^{\star}$ Georgina recorrió de la ciudad

c. ${ }^{\star}$ Etelvina recorrió al parque

d. *Ramona recorrió del parque a la casa

Ahora bien, a pesar de la ausencia inherente de los componentes de dirección y cambio de lugar, recorrer sí denota un estado de cosas télico. Obsérvese que es un ítem que se puede instanciar en construcciones resultativas, como en (32a), y pasivas, como en (32b), posibilidad que, por supuesto, no tienen los procesos inherentemente indelimitados como, por ejemplo, arrastrarse - $(32 \mathrm{~d})-$ :

\section{(32)a. La ciudad ya está completamente recorrida \\ b. La ciudad ha sido completamente recorrida \\ c. Juan se arrastró por la ciudad \\ d. ${ }^{*}$ La ciudad ya está completamente arrastrada}

Un rasgo importante adicional que permite observar un ejemplo como (32a) es que, a diferencia de con las realizaciones stricto sensu, el foco resultativo está en la trayectoria y no en el tema, como se puede seguir de la agramaticalidad de ${ }^{\star}$ Marina está recorrida (cf. con Ulises está trepado en árbol y ${ }^{\star}$ el árbol está trepado).

A pesar de que en español recorrer es el único verbo de base de esta subclase, es importante registrar la posibilidad de este patrón de lexicalización. Nada impide que en una lengua dada la telicidad pueda ser excluyente de los rasgos de cambio de estado y dirección (y de punto de arribo-meta). Queda abierta la posibilidad de registrar predicados de este tipo en lenguas aún no descritas con grano fino.

Independientemente de tal posibilidad, la pertinencia de plantear la existencia de la subclase queda asegurada por el hecho de que aquí se adscriben también las construcciones transitivas-no causativas de los verbos de realización derivados de actividades, mencionados ya en el apartado anterior: caminar, correr, rodar, nadar, serpentear y reptar: 
(33)a. Julisa caminó toda la ciudad descalza

b. Romelia rodó la colina entera

c. Arturo nadó el río cuesta abajo

d. Fabián reptó el camino que nos separaba como una serpiente

Se trata de construcciones que no implican un cambio de lugar, pues que 'Julisa haya caminado toda la ciudad', por ejemplo, no supone que 'antes no estaba en la ciudad y que ahora sí lo esté. También es interesante notar que el foco resultativo de estas construcciones está en la trayectoria codificada como objeto directo y no en el tema; así, aunque su gramaticalidad es marginal, podemos decir algo como La ciudad ya está bien caminada, pero no algo como *Julisa ya está bien caminada.

Es decir, las construcciones transitivas de los verbos de actividad se alinean en su semántica y en su comportamiento sintáctico con un predicado como recorrer. Juntos forman un subgrupo aparte de las realizaciones stricto sensu. En el cuadro 4 se presentan los rasgos o componentes que inherentemente forman parte de este tipo de realizaciones:

\begin{tabular}{|l|l|l|l|l|l|l|l|l|l|l|l|l|l|l|}
\hline Clase & Mov & Desp & CL & Dire & Man & Telic & Punt & Tem & Fuen & Meta & Ruta & PR & LRu & Tray \\
\hline Real II & + & + & - & - & $+/-$ & + & - & + & - & - & - & - & - & + \\
\hline
\end{tabular}

Cuadro 4. Rasgos semánticos de las realizaciones

sin 'dirección' y 'sin cambio de lugar'

3.2 Subclases de los verbos de movimiento de logro

Los verbos que pertenecen a esta clase, tales como llegar, salir, partir, entrar, etc., normalmente son agrupados junto con los de realización en la clase de los verbos direccionales o de desplazamiento (ver, por ejemplo, Morimoto, 2001). Sin embargo, estos que aquí abordamos lexicalizan del esquema conceptual del movimiento solo una de las fases, ya sea la de 'inicio' o 'partida', o la de 'término' o 'arribo', y dejan fuera la fase intermedia de desplazamiento; es decir, denotan el movimiento como un cambio de lugar puntual; en una construcción progresiva como Juan está llegando, el tema se acerca a la meta pero aún no está en contacto con ella, por lo que se focaliza un momento anterior 
del proceso propiamente de 'llegar'; en tal construcción, la fase de arribo tal cual queda fuera del alcance de la predicación.

Los logros de movimiento se dividen en dos subgrupos: a) verbos que lexicalizan la dirección y tienen foco en la fuente o en la meta y b) verbos sin dirección que se construyen con un punto de referencia. En los dos siguientes apartados analizamos estas dos subclases de manera separada.

\subsubsection{Logros que lexicalizan dirección}

Se trata de predicados que, como ya se mencionó, tienen un foco inherente en cualquiera de las dos fases delimitativas del movimiento, ya sea la de 'inicio' (salir, irse, ${ }^{10}$ partir, marcharse, ausentarse y escaparse), como en (34ab) o la de 'arribo' (entrar, llegar, meterse, arribar, acceder, aterrizar y asistir, entre otros), como en (34cd).

\section{(34)a. Nidia salió del bosque llena de lodo \\ b. Norma se fue del país por miedo a la violencia \\ c. Nancy entró a la cantina por una cerveza \\ d. Nury asistió a la reunión de fin de año}

De esta forma, un rasgo importante que necesariamente está presente con estos predicados es el de dirección, ya sea, justamente, 'desde la fuente' o 'hacia la meta'. Dentro del marco conceptual es posible inferir que existe un desplazamiento anterior al arribo del tema a la meta, o posterior a que el tema abandone la fuente, sin embargo, en sentido estricto, este tipo de verbos únicamente perfila el momento en el que se da el cambio de lugar.

Un rasgo que sí comparten estos logros con las realizaciones stricto sensu es el hecho de que el foco resultativo del cambio de lugar está en el tema: Etelvina llegó a la casa implica que 'Etelvina ha pasado a estar en la casa' y no que 'la casa ha pasado a estar llegada'.

\footnotetext{
${ }^{10}$ Como se propone en Ibáñez (2005) la versión pronominalizada de ir tiene ya un foco argumental en la fuente: irse básicamente significa 'ya no estar en el punto de partida'.
} 
Ahora bien, el hecho de que del marco conceptual del movimiento se pueda recuperar el evento completo de punto a punto, hace posible que estos predicados se puedan combinar, sin importar la fase delimitativa que lexicalizan, con locativos de fuente $-(35 \mathrm{ab})$ - o de meta - (35cd) - o con ambos, incluyendo un punto de referencia - (35ef) - , pero no con complementos de locación-ruta - (35gh) - que, como veremos, son propios únicamente de las actividades:
(35)a. Edmundo se marchó de su casa
b. Lorena entró de la calle
c. Lorena entró a la cantina
d. Edmundo se marchó al bar
e. Edmundo se marchó de su casa al bar por el parque
f. Lorena entró de la calle a la cantina por la puerta trasera
g. ${ }^{\star}$ Edmundo se marchó en la casa
h. ${ }^{\star}$ Lorena entró en la cantina (solo lectura de meta, no de loca- ción-ruta)

Lo que hay que señalar en este respecto es que, a pesar de lo ilustrado en (35), en datos de uso (Ibáñez, 2005), los verbos del tipo entrar tienden mayoritariamente a construirse exclusivamente con complementos de meta y los del tipo salir mayoritariamente con fuentes.

De forma interesante, aunque inherentemente lexicalizan la dirección, dado su carácter puntual, los ítems que aquí estamos analizando, a diferencia de los de realización, no se combinan del todo bien con complementos preposicionales de dirección - (36ab) - , aunque los verbos de fuente tienen más posibilidades en este sentido - $(36 \mathrm{~cd})$ -

\section{(36)a. ${ }^{*}$ Corina llegó para/hacia su casa \\ b. ? Fabiola se metió para/hacia la escuela \\ c. El barco partió para/hacia el oriente \\ d. ?Romario se escapó para/hacia el desierto}

Ahora bien, el rasgo sintáctico más importante que diferencia a este tipo de logros direccionales de las realizaciones del 
mismo tipo, es el hecho de que nunca se construyen transitivamente, como muestran los ejemplos prima de (37):
(37)a. Popeye llegó al bar
a. * Popeye llegó el bar
b. Archi partió de Riverdale
b. ${ }^{\star}$ Archi partió Riverdale

Finalmente, en relación con los verbos de esta subclase, solo hay que agregar que típicamente no lexicalizan la manera, al menos no hemos identificado en esta investigación uno que sí lo haga. En el cuadro 5 abajo se presentan los rasgos inherentes de estos predicados:

\begin{tabular}{|l|l|l|l|l|l|l|l|l|l|l|l|l|l|l|}
\hline Clase & Mov & Desp & CL & Dire & Man & Telic & Punt & Tem & Fuen & Meta & Ruta & PR & LRu & Tray \\
\hline Log I & + & - & + & + & - & + & + & + & $+/-$ & $+/-$ & - & - & - & - \\
\hline
\end{tabular}

Cuadro 5. Rasgos semánticos de los logros que lexicalizan

dirección (fuente o meta)

3.2.2 Logros sin dirección y que se construyen con un punto de referencia

Es este un grupo de ítems que ha sido poco estudiado en la bibliografía. Entre los verbos que lo conforman están pasar, cruzar, franquear, traspasar y atravesar, los cuales no suelen ser adscritos a ninguna de las clases típicamente mencionadas en los trabajos de referencia. Como logros, son predicados inherentemente puntuales que presentan en su proyección oracional un complemento de 'punto de referencia' codificado como objeto directo:

(38)a. Melania pasó la frontera con fachuca

b. Escarlata cruzó el vado de un salto

c. El camión franqueó la barrera sin detenerse

d. La flecha traspasó la pared

Las ejemplificadas en (38) son construcciones transitivas no causativas; Melania pasó la frontera no implica que 'Melania causó que la frontera esté en otro lugar'. 
El carácter puntual de estos predicados se puede constatar en el hecho de que no se combinan con modificadores temporales durativos, como muestran los ejemplos de (39), que para funcionar adecuadamente tienen que interpretarse como iterativos. $^{11}$

(39)a. ??Melania pasó la frontera durante una hora

b. ??Escarlata cruzó el vado durante una hora

Solo algunos de estos verbos pueden, aunque de manera menos frecuente, codificar dicho punto de referencia como un complemento preposicional introducido, generalmente, con por:

(40)a. Melania pasó por la frontera con fayuca

b. Escarlata cruzó por el vado de un salto

c. ${ }^{\star}$ El camión franqueó por la barrera sin detenerse

d. ${ }^{\star}$ La flecha traspasó por la pared

Como se señaló en el subapartado 2.3, el punto de referencia alude a un espacio locativo que delinea el movimiento, pero no como camino del recorrido, sino solo como un 'punto de cruce, pues no se implica un desplazamiento. El rasgo de puntualidad de los predicados es lo que permite distinguir semánticamente este tipo de locativo de las rutas propiamente (que son un 'camino') y de las trayectorias (que sintetizan un 'desplazamiento de punto a punto').

Además de ser básicamente transitivos y de requerir un punto de referencia, este tipo de logros se distinguen de los abordados en el apartado anterior porque no se construyen con complementos de fuente y de metas - ejemplos no-prima de (41) - , salvo en ciertos usos muy específicos - ejemplos prima de (41)-:

\footnotetext{
${ }^{11}$ Es cierto que al menos cruzar y atravesar pueden tener una interpretación durativa con cierto tipo de locativos cuyo referente es un espacio de extensión amplia. Por ejemplo, Cruzó el bosque durante una hora y Atravesó el bosque durante una hora son oraciones posibles.
} 
(41)a. * Melania pasó a la frontera / de la frontera

a. Melania pasó a los Estados unidos / de los Estados Unidos

b. *Escarlata cruzó al vado / del vado

b. Escarlata cruzó a los Estado Unidos / de los Estados Unidos

Esta falta de posibilidad de proyectar a la meta y a la fuente se debe a la carencia inherente del rasgo de dirección; o, si se quiere ver así, la misma idea de 'cruzar' implica una bidireccionalidad. Se trata, pues, en el caso de los ítems analizados en este subapartado, de verbos de logro, télicos y con cambio de lugar, pero que no son direccionales.

También hay que señalar que el cambio de lugar implica un foco resultativo no en el tema, como en el caso de los logros direccionales, sino en el punto de referencia. Así, Escarlata cruzó el vado implica que 'el vado ya está cruzado', pero no que 'Escarlata ya está cruzada.' ${ }^{12}$

Finalmente, como es común con la mayoría de los verbos télicos, la manera no es lexicalizada por este tipo de predicados. En el cuadro 6 se resumen los rasgos y componentes de los logros sin dirección:

\begin{tabular}{|l|l|l|l|l|l|l|l|l|l|l|l|l|l|l|}
\hline Clase & Mov & Desp & CL & Dire & Man & Telic & Punt & Tem & Fuen & Meta & Ruta & PR & LRu & Tray \\
\hline Log II & + & - & + & - & - & + & + & + & - & $+/-$ & - & + & - & - \\
\hline
\end{tabular}

Cuadro 6. Rasgos semánticos de los logros sin dirección

y con punto de referencia

\subsection{Subclases de los verbos de movimiento de actividad}

Es esta la clase que, creemos, se beneficia más, en términos de su descripción, de la adopción de un juego de componentes más específicos. Tradicionalmente, los predicados que aquí incluimos en cuatro subgrupos suelen ser adscritos de manera genérica a la clase de los verbos de manera de movimiento ( $c f$., por ejemplo, Morimoto, 2001). Como aquí mostramos, solo un subgrupo de ellos está formado por ítems que efectivamente lexicalizan

\footnotetext{
${ }^{12}$ Esta lectura es posible en el caso de un uso causativo de cruzar, como en El general cruzó a Escarlata del otro lado del río, que sí implica que 'Escarlata ya está cruzada'.
} 
la manera en el sentido de Talmy (1985). Así, por ejemplo, correr y arrastrarse sí implican la forma del movimiento del tema que se desplaza, pero ciertamente no transitar, andar, avanzar, adentrarse, deambular y rondar. En este sentido, la propuesta de Ibáñez (2005) de considerarlos juntos en una clase más amplia aspectualmente congruente, la de las actividades, resulta ya una ganancia descriptiva y analítica. Básicamente, lo que todos estos ítems comparten es el hecho de focalizar inherentemente la fase intermedia del movimiento, la de desplazamiento, dejando fuera de su alcance las etapas delimitativas de inicio y de término. Son, pues, predicados atélicos y durativos que, en general, tienden a construirse de forma intransitiva, acompañados de complementos locativos de ruta y locación-ruta, pero no de fuentes, metas ${ }^{13}$ y trayectorias.

En lo que sigue, hacemos la descripción de cuatro subclases semántica y sintácticamente pertinentes.

\subsubsection{Actividades propias}

Los verbos que forman este subgrupo lexicalizan únicamente el desplazamiento. Son los más básicos de la clase general de las actividades. Se trata de ítems como andar, desplazarse, transitar, pasear, circular, ${ }^{14}$ viajar y seguir. Dado que perfilan al tema en desplazamiento, denotan procesos atélicos y durativos. Pero, como se puede ver en el cuadro 7, más allá de estos rasgos, este tipo de ítems no implica ninguno de los otros componentes del esquema conceptual del movimiento, como la dirección o la manera, pero sí su combinabilidad con complementos de ruta y locaciones-ruta, que delinean el camino sobre el que se lleva a cabo el desplazamiento.

\footnotetext{
${ }^{13}$ Aunque como vemos más adelante, algunas subclases sí se combinan con metas.

${ }^{14}$ Aunque el diccionario de la RAE define circular como un verbo de manera "Andar o moverse en derredor" (DLE: consulta en línea, 13 de julio de 2018), datos de uso muestran que tal manera se ha 'deslavado' y que el verbo se utiliza para denotar solo desplazamiento. Lo mismo sucede con andar, que en el mismo diccionario se define como "Ir de un lugar a otro dando pasos" (DLE: consulta en línea, 13 de julio de 2018), y a pesar de ello se puede decir andar en camión, andar saltando, andar en bici, andar caminando, etc.
} 


\begin{tabular}{|l|l|l|l|l|l|l|l|l|l|l|l|l|l|l|}
\hline Clase & Mov & Desp & CL & Dire & Man & Telic & Punt & Tem & Fuen & Meta & Ruta & PR & LRu & Tray \\
\hline Act I & + & + & - & - & - & - & - & + & - & - & + & - & + & - \\
\hline
\end{tabular}

Cuadro 7. Rasgos semánticos de las actividades propias

No hay nada en un ítem como andar, en una oración como (42a), que indique la manera del desplazamiento del tema; esta puede indicarse con modificadores adicionales, según se ejemplifica en (42b) y (42c):

(42)a. Lotario anda solo por el bosque

b. Lotario anda solo por el bosque caminando

c. Lotario anda solo por el bosque a caballo

Lo mismo sucede con la dirección, que puede ser codificada de forma adicional, como en las oraciones de (43):

(43)a. Clotilde transita por la avenida en dirección al oeste

b. Clotilde se desplaza hacia atrás por la avenida

En los ejemplos de (43) se puede ver que las actividades propias se construyen bien con complementos de ruta, dado su carácter atélico. Por la misma razón se acompañan también con complementos de locación-ruta, como en (44ab), pero no con fuentes y metas $-(44 \mathrm{~cd})-{ }^{15}$

(44)a. Matilde transita muy a gusto en la avenida principal

b. Matilde anda en el bosque de Chapultepec

c. ${ }^{\star}$ Matilde circula de la avenida principal

d. ${ }^{\star}$ Clotilde pasea a la montaña

Ahora bien, un comportamiento sintáctico un tanto inesperado, pero muy interesante, de los predicados pertenecientes

\footnotetext{
${ }^{15}$ Los verbos en cuestión sí se pueden acompañar de una fuente y una meta simultáneamente, Matilde transita de su casa a la escuela todos los días. Se trata de una combinación de componentes - fuente y meta- que activa el esquema completo del movimiento como desplazamiento de punto a punto. El punto es que en datos de uso estos casos casi no se presentan (Ibáñez, 2005; Lecumberri, 2011; Delgado, 2019).
} 
a esta subclase es el hecho de que algunos de ellos pueden proyectar oraciones transitivas, no causativas, en las que la ruta se codifica como objeto directo, según se ejemplifica en (45ab). Este objeto directo también puede tener como referente la 'cantidad de espacio recorrido', en lo que aquí llamamos rutas de cantidad, como en $(45 \mathrm{~cd})$ :

\section{(45)a. Adriano transita la avenida principal todos los días \\ b. Adriano anduvo el camino errado durante horas \\ c. Adriano circula 10 kilómetros sin parar \\ d. Adriano pasea una distancia larga por las mañanas}

Es importante notar que las oraciones de (45) son atélicas, como lo prueba la presencia de complementos durativos del tipo todos los días o durante horas. En este sentido no suponen ni un cambio de lugar ni un resultado. Adriano transita la avenida principal no implica que Adriano 'no estaba en la avenida y pasó a estar en la avenida', o que terminó su transitar en algún punto.

Estos verbos son, pues, los más emblemáticos como actividades de desplazamiento: no lexicalizan ninguno de los demás componentes del esquema conceptual del movimiento.

\subsubsection{Verbos de actividad con dirección}

Este subgrupo está formado por ítems que como actividades focalizan un desplazamiento, pero que, contra lo esperado, implican tal desplazamiento como dirigido u orientado; es decir, lexicalizan también el rasgo de dirección. Más interesante aún, el desplazamiento no culmina en una meta y, por tanto, no deriva en un cambio de lugar. Se trata, pues, de eventos atélicos. Los verbos que corresponden a esta subclase son avanzar, retroceder, enfilarse, adentrarse, internarse, acercarse, alejarse, aproximarse $\mathrm{y}$ dirigirse.

La dirección puede corresponder a un valor definido en el eje horizontal de un plano cartesiano: avanzar implica 'desplazarse hacia adelante'; a un valor en la oposición adentro-afuera: adentrarse refiere 'desplazarse hacia adentro', o un valor de orientación general hacia un punto, dirigirse significa 'desplazarse ha- 
cia algún lugar'. Aunque el rasgo de dirección está lexicalizado, puede ser expresado adicionalmente como un complemento preposicional que especifica el rumbo de la dirección, como en los ejemplos no-prima de (46):

\section{(46)a. Moctezuma avanzó hacia la pirámide \\ a. * Moctezuma avanzó hacia atrás \\ b. Cortés se adentró hacia el corazón del país \\ b. $\quad{ }^{\star}$ Cortés se adentró hacia afuera}

Los ejemplos prima, por su parte, muestran que el rasgo de dirección sí está lexicalizado y que el valor inherente no puede ser contradicho. Hay que señalar que los complementos de dirección son comúnmente introducidos por la preposición hacia, pero también pueden ir, en el caso de ciertos ítems, con la preposición $a$ :

\section{(47)a. Darío se acercó a la puerta de Atenas \\ b. Artajerjes se aproximó a las orillas del Éufrates}

Lo que es importante señalar es que en estos casos el locativo introducido por $a$ no es una meta. En (47a) no se implica que 'Darío esté ya en las puertas de Atenas'; tampoco en (47d) se supone que 'Artajerjes efectivamente se encuentre en las orillas del río' Se trata, pues, de complementos direccionales y no de meta y en tales usos los predicados en cuestión siguen siendo atélicos.

Al igual que todos los demás verbos de actividad, los predicados que nos competen en este apartado se construyen primordialmente con un complemento de ruta que delinea el camino sobre el que se lleva a cabo el desplazamiento (ejemplos no-prima de (48)), pero, a diferencia de las actividades propias - los del subgrupo anterior- no pueden ser usados con complementos de locación-ruta, como muestran las oraciones prima de (48):

(48)a. Julio César avanzaba por la Toscana

a. ??Julio César avanzaba en la Toscana 


\section{b. Craso retrocedió por la Campania \\ b. ??Craso retrocedió en la Campania}

Las excepciones son adentrarse e internarse, que sí se usan con complementos locativos introducidos por la preposición en -(49)—:

(49)a. Druso se adentró en los bosques de Tracia (se desplazó más adentro por los bosques)

b. Claudio se internó en el palacio (se desplazó más adentro del palacio)

Por último, en lo tocante a este subgrupo, hay que señalar que al menos verbos como avanzar y retroceder, también pueden, como algunos miembros de otras subclases, proyectar oraciones transitivas no causativas:

(50)a. Julio César avanzó tres kilómetros por la Toscana (los avanzó)

a.' *Julio César avanzó la Toscana

b. Craso retrocedió diez pasos (los retrocedió)

b. $\quad{ }^{\star}$ Craso retrocedió la Campania

Los ejemplos (50a) y (50b) muestran que efectivamente avanzar y retroceder se usan en construcciones propiamente transitivas, como lo muestra la posibilidad de clitización pronominal de las frases en negritas. Hay que notar, sin embargo, que se trata de lo que arriba hemos denominado complementos de 'cantidad-ruta' o 'distancia', y no estrictamente de complementos de ruta. Estas, como dejan ver (50a') y (50b'), no pueden ser objeto directo.

El resumen de los rasgos y componentes lexicalizados por los predicados de la subclase aquí analizada se presenta en el cuadro 8:

\begin{tabular}{|l|l|l|l|l|l|l|l|l|l|l|l|l|l|l|}
\hline Clase & Mov & Desp & CL & Dire & Man & Telic & Punt & Tem & Fuen & Meta & Ruta & PR & LRu & Tray \\
\hline Act II & + & + & - & + & - & - & - & + & - & - & + & - & $-/+$ & - \\
\hline
\end{tabular}

Cuadro 8. Rasgos semánticos de los predicados

de actividad con dirección 
3.3.3 Verbos de actividad con manera de la figura

En esta subclase se adscriben los ítems que tradicionalmente son identificados como los opuestos de los ítems direccionales (en el sentido genérico de path). Se trata de aquellos que lexicalizan, junto con el desplazamiento, la manera en la que el tema se mueve al desplazarse: caminar, correr, arrastrarse, rodar, volar, nadar, marchar, escurrirse, deslizarse, reptar, renquear y serpentear, zigzaguear, gatear, entre otros. Son básicamente atélicos y carecen en su semántica de la idea de dirección.

El hecho de que estos ítems inherentemente implican el rasgo de manera se puede constatar en su poca combinabilidad con otros ítems de la misma clase en la forma de modificadores - (51ab) - En cambio, su aparición con verbos de otras subclases del movimiento, en la misma función de modificadores es normal - $(51 \mathrm{~cd})-$ :

\section{(51)a. ??Adalberto camina marchando}

b. ??Julieta corre caminando

c. Julieta salió de su casa deslizándose

d. Lucio avanzaba reptando

Datos de corpus (Ibáñez, 2005), dejan ver que estos verbos suelen usarse acompañados de complementos preposicionales de ruta, pero nada impide que también aparezcan con locaciones-ruta:

\section{(52)a. Ludmila se arrastra por la callejuela / en la callejuela}

b. Toya rodó por la explanada / en la explanada

c. Cudberto repta por la empalizada / en la empalizada

Es decir, como verbos de actividad, muestran comportamientos similares a los del tipo de andar, transitar, pasear, etc. Es posible que por eso normalmente han sido analizados como pertenecientes al mismo grupo. La diferencia estriba, además de la presencia-ausencia del propio rasgo de manera, en el hecho de que los analizados en este subapartado suelen aparecer muy frecuentemente en construcciones télicas con la presencia de complementos de meta, fenómeno que abordamos en el inciso 
3.1.1 y que ilustramos con los ejemplos prima de (28), que aquí volvemos a presentar como (53):

\section{(53)a. Rogelio caminó hasta el gimnasio \\ b. Joaquín se arrastró a la cantina}

Como también mencionamos anteriormente, la presencia de los complementos meta efectivamente transforma su identidad aspectual, convirtiéndolos en eventos télicos y, por lo tanto, en realizaciones.

De la misma forma, en el apartado 3.1.2 postulamos que otra construcción de los verbos de manera se puede adscribir a la subclase de las realizaciones sin cambio de estado. En este caso se trata de las oraciones transitivas no causativas en las que la ruta aparece codificada como objeto directo, según se ilustra en los ejemplos de (33), reintroducidos aquí bajo (54):

\section{(54)a. Julisa caminó toda la ciudad descalza \\ b. Romelia rodó la colina entera \\ c. Arturo nadó el río cuesta abajo \\ d. Fabián reptó el camino que nos separaba como una serpiente}

Como vimos, estas son construcciones que no implican un cambio de lugar, pues que 'Julisa haya caminado toda la ciudad', por ejemplo, no supone que 'antes no estaba en la ciudad y que ahora sí lo esté. En este sentido, caminar transitivo no codifica una meta, ni una trayectoria (ver apartado 3.2.1) sino que su objeto directo es una ruta. Esto es un indicador claro de su adscripción de base como un verbo de actividad y de que como tal focaliza primordialmente solo la fase intermedia de desplazamiento. En el cuadro 9 se resumen los rasgos o componentes de los verbos de actividad con manera, dejando de lado sus rasgos cuando se comportan como realizaciones:

\begin{tabular}{|l|l|l|l|l|l|l|l|l|l|l|l|l|l|l|}
\hline Clase & Mov & Desp & C L & Dire & Man & Telic & Tem & Punt & Fuen & Meta & Ruta & PR & L Ru & Tray \\
\hline Act III & + & + & - & - & + & - & + & - & - & - & + & - & + & - \\
\hline
\end{tabular}

Cuadro 9. Rasgos semánticos de los predicados

de actividad con manera de la figura 
3.3.4 Verbos de actividad con manera del desplazamiento Este subgrupo está formado por verbos como merodear, deambular, rondar, callejear, peregrinar, ${ }^{16}$ vagar y vagabundear. La diferencia entre los predicados de esta clase y los de la anterior radica en que con estos la manera lexicalizada es relativa no a la forma de movimiento del tema o de la figura, sino del tipo de desplazamiento que dicho participante realiza. En general, implican inherentemente un desplazamiento en sí mismo indefinido, 'no ordenado', por decirlo de alguna manera, 'sin dirección y sin fin', como sucede con deambular en (55a); este verbo no denota nada acerca del tipo de movimiento del limosnero, y por ello puede ser modificado por un predicado de manera en forma participial, en este caso cojeando. De la misma forma, (55b) deja ver que deambular no se acompaña bien con complementos direccionales, y esto es en virtud de que efectivamente el rasgo 'andar de un lado para el otro y sin dirección fija’ está lexicalizado.

(55)a. El limosnero deambula por la ciudad cojeando de forma lastimosa

b. ??El limosnero deambula con dirección al centro de la ciudad

Del hecho de que se trate de predicados atélicos se desprende su combinatoria semánticamente natural, y muy frecuente en datos de uso (Delgado, 2019; Huila, 2020), con complementos de ruta y de locación-ruta, como en los ejemplos de (56ac), no así con complementos télicos del tipo fuente y meta, como en (56bd).

(56)a. Juan merodea por el jardín / en el jardín

b. ${ }^{*} J u a n$ merodea al parque / del parque

c. Juan ronda por las cantinas / en las cantinas

d. ${ }^{\star} J u a n$ ronda a las cantinas / de las cantinas

Este último comportamiento, la incompatibilidad con metas y fuentes, distingue claramente a estos verbos de los de la

\footnotetext{
${ }^{16}$ En los sentidos que marca el diccionario de la RAE como primera y tercera acepción: "Dicho de una persona: andar por tierras extrañas" y "Andar de un lugar a otro buscando o resolviendo algo" (DLE: consulta en línea, 8 de enero de 2019).
} 
clase de 'manera de la figura' que, como señalamos arriba, sí se construyen comúnmente con locativos télicos.

En el cuadro 10 se presentan los rasgos presentes inherentemente en este tipo de predicados:

\begin{tabular}{|l|l|l|l|l|l|l|l|l|l|l|l|l|l|l|}
\hline Clase & Mov & Desp & CL & Dire & Man & Telic & Punt & Tem & Fuen & Meta & Ruta & PR & LRu & Tray \\
\hline Act IV & + & + & - & - & + & - & - & + & - & - & + & - & + & - \\
\hline
\end{tabular}

Cuadro 10. Rasgos semánticos de los predicados de actividad con manera del desplazamiento

Ahora bien, al igual que las actividades propias y que los verbos de manera de la figura, algunos verbos de esta clase también se instancian en construcciones transitivas-no causativas:

(57)a. Los ladrones merodean la casa

b. Esteban ronda las cantinas del pueblo

La gran diferencia es que los que analizamos en este apartado no pueden tener objetos directos de ruta-distancia:

(58)a. ??Los ladrones merodean tres kilómetros

b. ??El limosnero deambula un kilómetro

c. Esteban caminó dos kilómetros

d. Rubén transitó dos kilómetros

Tampoco se combinan adecuadamente con complementos de dirección introducidos por hacia o por para, como muestran los ejemplos de (59), justamente porque lexicalizan como manera del desplazamiento el rasgo 'andar de un lado a otro, sin dirección fija'; es decir implican inherentemente un movimiento inespecífico y no direccional.

(59)a. ??Los ladrones merodean hacia la ciudad

b. ??El limosnero deambula para la iglesia

Hasta aquí la subclase de los verbos de actividad con manera del desplazamiento. 


\section{En el cuadro 11 se muestran comparativamente los rasgos} comunes y diferenciales de las cuatro subclases de actividades:

\begin{tabular}{|l|l|l|l|l|l|l|l|l|l|l|l|l|l|l|}
\hline Clase & Mov & Desp & CL & Dire & Man & Telic & Punt & Tem & Fuen & Meta & Ruta & PR & LRu & Tray \\
\hline Act I & + & + & - & - & - & - & - & + & - & - & + & - & + & - \\
\hline Act II & + & + & - & + & - & - & - & + & - & - & + & - & $+/-$ & - \\
\hline Act III & + & + & - & - & + & $+/-$ & - & + & - & $+/-$ & + & - & + & - \\
\hline Act IV & + & + & - & - & + & - & - & + & - & - & + & - & + & - \\
\hline
\end{tabular}

Cuadro 11. Rasgos semánticos de los predicados

de movimiento de actividad

\section{Por último, en el cuadro 12 se presenta un resumen de la} propuesta de clasificación de los verbos de movimiento no causativos en español:

\begin{tabular}{|c|c|c|}
\hline Grupo & Subgrupo & Verbos \\
\hline \multirow[t]{2}{*}{ Realizaciones } & Realizaciones stricto sensu & $\begin{array}{l}\text { Ir, venir, regresar, volver, trasladarse, } \\
\text { subir, bajar, ascender, descender, trepar, } \\
\text { escalar, encaminarse, retornar, acudir; y } \\
\text { las construcciones télicas de los verbos de } \\
\text { actividad de 'manera de la figura'. }\end{array}$ \\
\hline & $\begin{array}{l}\text { Realizaciones sin dirección } \\
\text { y sin cambio de lugar }\end{array}$ & $\begin{array}{l}\text { Recorrer y las construcciones transitivas-no } \\
\text { causativas de los verbos de 'manera de la figura'. }\end{array}$ \\
\hline \multirow[t]{2}{*}{ Logros } & $\begin{array}{l}\text { Verbos que lexicalizan } \\
\text { dirección (fuente o meta) }\end{array}$ & $\begin{array}{l}\text { Salir, irse, partir, marcharse y ausentarse y } \\
\text { escaparse; entrar, llegar, meterse, arribar, } \\
\text { acceder, aterrizar y asistir. }\end{array}$ \\
\hline & $\begin{array}{l}\text { Verbos con punto de } \\
\text { referencia }\end{array}$ & Pasar, cruzar, franquear, traspasar y atravesar. \\
\hline \multirow[t]{4}{*}{ Actividades } & $\begin{array}{l}\text { Actividades propias (solo } \\
\text { desplazamiento) }\end{array}$ & $\begin{array}{l}\text { Andar, desplazarse, transitar, moverse, pasear, } \\
\text { circular, viajar y seguir. }\end{array}$ \\
\hline & Actividades con dirección & $\begin{array}{l}\text { Avanzar, retroceder, enfilarse, adentrarse, } \\
\text { internarse, acercarse, alejarse, aproximarse y } \\
\text { dirigirse. }\end{array}$ \\
\hline & $\begin{array}{l}\text { Actividades de 'manera de } \\
\text { la figura' }\end{array}$ & $\begin{array}{l}\text { Caminar, correr, arrastrarse, rodar, volar, nadar, } \\
\text { marchar, escurrirse, deslizarse, reptar, renquear, } \\
\text { serpentear, zigzaguear, gatear y desfilar. }\end{array}$ \\
\hline & $\begin{array}{l}\text { Actividades de 'manera del } \\
\text { desplazamiento' }\end{array}$ & $\begin{array}{l}\text { Merodear, deambular, peregrinar, rondar, vagar, } \\
\text { callejear y vagabundear. }\end{array}$ \\
\hline
\end{tabular}

Cuadro 12. Clasificación general de los verbos de movimiento no causativos 


\section{Conclusión}

El marco conceptual del movimiento, así como los elementos semánticos que lo integran y sus posibles proyecciones sintácticas, ha sido un tema ampliamente estudiado desde muy distintos puntos de vista. Con base en el trabajo pionero de Talmy (1985), las clasificaciones que hasta ahora se nos ofrecen de los verbos de movimiento del español reconocen principalmente dos grupos: verbos de manera y verbos de dirección.

El presente trabajo ofrece una clasificación mucho más fina y detallada al contemplar catorce rasgos o participantes semánticos cuyas distintas combinatorias danaportan pie al amplio inventario léxico del movimiento en el español, lo que da como resultado ocho clases distintas con características semánticosintácticas propias.

Los rasgos semánticos y participantes que se tomaron en cuenta son: los rasgos aspectuales de puntualidad y telicidad; los participantes tema, fuente, ruta, meta, punto de referencia, locación-ruta y trayectoria; y los rasgos paramétricos de desplazamiento, movimiento, manera, cambio de lugar y dirección.

En el presente estudio se propone por primera vez considerar los locativos punto de referencia, locación-ruta y trayectoria. Asimismo, es importante señalar que se consideran dos tipos de manera, distinción que no se considera en trabajos previos. Por un lado, tenemos la manera de la figura, considerada desde la propuesta de Talmy (1985) en predicados como deslizar, caminar, correr, etc., y, por otro lado, la manera del desplazamiento, que no se refiere a la manera en la que se mueve el tema sino a una forma de desplazarse, presente en predicados como deambular, vagar y merodear.

La clasificación que aquí se presenta parte de tres grandes grupos aspectuales propuestos por Ibáñez (2005): las realizaciones, los logros y las actividades, y al combinar estos tres grupos con los rasgos paramétricos y los distintos participantes locativos, es posible identificar ocho grupos: dos tipos de realizaciones, dos tipos de logros y cuatro tipos de actividades.

De esta forma, un evento de movimiento en español puede ser un desplazamiento télico de punto a punto que implica 
una dirección y un cambio de lugar (ir, venir, regresar, llevar, etc.), un desplazamiento télico sin dirección y que no implica un cambio de lugar (recorrer), un evento puntual con cambio de locación y dirección (salir, entrar, partir, arribar, etc.), un cambio de locación a partir de un punto de referencia y sin un punto de origen o un punto final en el movimiento (pasar, cruzar, etc.), un desplazamiento atélico (andar, circular, transitar, etc.), un desplazamiento atélico con dirección (avanzar, adentrarse, internarse, etc.), un desplazamiento atélico con manera de la figura (caminar, correr, deslizar, etc) y un desplazamiento atélico con manera en el desplazamiento (deambular, vagar, merodear, etc.).

Faltaría poner a prueba la utilidad de esta propuesta teórico-metodológica en la descripción de lenguas de distinta identidad tipológica.

\section{Referencias}

Aske, J. (1989). Path predicates in English and Spanish: A closer look. En Proceedings of the Fifteenth Annual Meeting of the Berkeley Linguistics Society (pp. 1-14). Berkeley: Linguistics Society.

Cifuentes Honrubia, J. L. (1988-1989). Sobre las construcciones locales en español. Estudios de Lingüística, 5, 145-181.

Crego García, M. V. (2000). El complemento locativo en espanol. Los verbos de movimiento y su combinatoria sintácticosemántica. Santiago de Compostela: Universidad de Santiago de Compostela.

Delgado, A. (2019). Análisis sintáctico-semántico de verbos de movimiento del tipo "andar" (tesis de licenciatura). Universidad Nacional Autónoma de México, Ciudad de México, México.

Desvillez-Bastuji, J. (1982). Structures des relations spatiales dans quelques langues naturales. Introduction à una théorie sémantique. Génave: Droz.

Dowty, D.R. (1979). Word Meaning and Montague Grammar. Dordrecht: Reidel. 
Evans, V. y Tyler, A. (2004). Rethinking English "Prepositions of Movement", The Case of To and Through, în H. Cuychens. En W. De Mulder, T. Mortelmans (eds.), Adpositions of Movement (Belgian Journal of Linguistics) ( pp. 247270). Ámsterdam: John Benjamins.

GRUBER, J. S. ([1965] 1976). Lexical Structure in Syntax and Semantics. Ámsterdam: MIT Press.

Gutiérrez, P. (2016). Complementos espaciales en construcciones de movimiento: sintaxis y semántica de la meta (tesis de maestría). Universidad Nacional Autónoma de México, Ciudad de México, México.

Helbig, G. (ed.) (1971). Beiträge zur Valenztheorie. Halle: Bibliographisches Institut / The Hague / París, Mouton.

Huila, V. (2020). Estructura argumental de verbos de movimiento de actividad (tesis de maestría). Universidad Nacional Autónoma de México, Ciudad de México, México.

IвÁÑEz, S. (2004). Estructuras verbales de dos objetos. Hacia una redefinición semántico-sintáctica del fenómeno: el caso de los verbos de poner y de quitar (tesis de doctorado). Universidad Nacional Autónoma de México, Ciudad de México, México.

IвÁÑEZ, S. (2005). Los verbos de movimiento intransitivos del español. México: Escuela Nacional de Antropología e Historia-Universidad Nacional Autónoma de México.

Jackendoff, R. (1983). Semantics and Cognition. CambridgeLondres: MIT Press.

Jackendoff, R. (1990). Semantic Structures. Cambridge-Londres: MIT Press.

LAmiroy, B. (1983). Les verbs de mouvement en français et espagnole. Ámsterdam: John Benjamins y Leuven University Press.

Lamiroy, B. (1991). Léxico y gramática del español: Estructuras verbales de espacio y de tiempo. Barcelona: Anthropos.

LeCumberri, B. (2011). Trayectorias con verbos de movimiento. Delimitación semántica y sintáctica (tesis de maestría). Universidad Nacional Autónoma de México, Ciudad de México, México. 
Morimoto, Y. (2001). Los verbos de movimiento. Madrid: Visor Libros.

Rohde, A. (2001). Analyzing path: The Interplay of Verbs, Prepositions and Construcional Semantics Ph.D. dissertation, Rice University, Department of Linguistics, Houston, Estados Unidos.

Slobin, D. I. (1996). Two ways to travel: Verbs of motion in English and Spanish. En M. Shibatani y S. A. Thompson (eds.), Grammatical Constructions: Their Form and Meaning (pp. 195-219). Oxford: Clarendon Press.

Stefanowitsch, A. y Rohde, A. (2004). The goal bias in the encoding of 'motion events'. En G. Radden y K. Panther (eds.), Studies in Linguistic Motivation (pp. 249-267). Berlín: De Gruyter Mouton.

TALmy, L. (1985). Lexicalization petterns: semantic structure in lexical forms. En T. Shopen (ed.), Language Typology and Syntactic Description Vol. III (pp. 57-149). Cambridge: Cambridge University Press.

Talmy, L. (2000). Toward a Cognitive Semantics. Cambridge: MIT Press.

Van Valin, R. y LaPolla, R. (1997). Syntax. Structure, meaning and function. Cambridge: Cambridge University Press.

VAN VAlin R. (ed.). (1993). Advances in role and reference grammar. Ámsterdam, John Benjamins.

Verspoor, M., Dirven, M. y Radden, G. (1999). Putting concepts together: Syntax. En R. Dirven y M. Verspoor (eds.), Cognitive Exploration of Language and Linguistics (pp. 87115). Ámsterdam/Filadelfia: John Benjamins.

Zwarts, J. (2010). A hierarchy of locations: Evidence from the encoding of direction in adpositions and cases. Language, 48(5), 983-1009. 